\title{
Diagnosing and discriminating between primary and secondary aneurysmal bone cysts
}

\author{
HIROMI SASAKI $^{1}$, SATOSHI NAGANO ${ }^{1}$, HIROFUMI SHIMADA ${ }^{1}$, MASAHIRO YOKOUCHI $^{1}$, \\ TAKAO SETOGUCHI ${ }^{2}$, YASUHIRO ISHIDOU ${ }^{3}$, OSAMU KUNIGOU ${ }^{1}$, \\ KOSUKE MAEHARA $^{1}$ and SETSURO KOMIYA ${ }^{1}$ \\ ${ }^{1}$ Department of Orthopedic Surgery; ${ }^{2}$ The Near-Future Locomotor Organ Medicine Creation Course; \\ ${ }^{3}$ Department of Medical Joint Materials, Graduate School of Medical and Dental Sciences, \\ Kagoshima University, Kagoshima 890-8520, Japan
}

Received January 28, 2016; Accepted December 1, 2016

DOI: $10.3892 / 01.2017 .5682$

\begin{abstract}
Aneurysmal bone cysts (ABCs) are benign bony lesions frequently accompanied by multiple cystic lesions and aggressive bone destruction. They are relatively rare lesions, representing only $1 \%$ of bone tumors. The pathogenesis of $\mathrm{ABCs}$ has yet to be elucidated. In the present study, a series of 22 cases of primary and secondary ABC from patients treated in Department of Orthopedic Surgery, Kagoshima University Hospital (Kagoshima, Japan) from 2001-2015 were retrospectively analyzed. The average age at the time of diagnosis of primary ABC was 17.9 years. Intralesional curettage and artificial bone grafting were performed in the majority of the patients with primary $\mathrm{ABC}$. The local recurrence rate following curettage for primary $\mathrm{ABC}$ was $18 \%$, and the cause of local recurrence was considered to be insufficient curettage. Although no adjuvant therapy was administered during the surgeries, it may assist the prevention of local recurrence in certain cases. The cases of secondary ABC were preceded by benign bone tumors, including fibrous dysplasia, giant cell tumors, chondroblastoma and non-ossifying fibroma. The features of the secondary $\mathrm{ABC}$ typically reflected those of the preceding bone tumor. In the majority of cases, distinguishing the primary $\mathrm{ABC}$ from the secondary $\mathrm{ABC}$ was possible based on characteristic features, including age of the patient at diagnosis and the tumor location. In cases that exhibit ambiguous features, including a soft tissue mass or a thick septal enhancement on the preoperative magnetic resonance images, a biopsy must be obtained in order to exclude other types of aggressive
\end{abstract}

Correspondence to: Dr Satoshi Nagano, Department of Orthopedic Surgery, Graduate School of Medical and Dental Sciences, Kagoshima University, 8-35-1 Sakuragaoka, Kagoshima 890-8520, Japan

E-mail: naga@m2.kufm.kagoshima-u.ac.jp

Key words: aneurysmal bone cyst, giant cell tumor, telangiectatic osteosarcoma, differential diagnosis, biopsy, fluid-fluid level bone tumors, including giant cell tumor, osteosarcoma and telangiectatic osteosarcoma.

\section{Introduction}

Aneurysmal bone cysts (ABCs) are benign intraosseous solitary lesions that consist of large thin-walled cavities, which are usually filled with blood when examined macroscopically (1). Although various theories have been proposed to describe their origin, including arteriovenous shunts, bleeding due to trauma and bleeding from a prior bony lesion, the pathogenesis of $\mathrm{ABCs}$ remains to be determined (2-4). ABCs are rare bony lesions that constitute only $1-2 \%$ of all bone tumors $(5,6)$. ABCs were initially considered to be pseudotumors; however, the identification of fusion genes has indicated that primary ABCs are true neoplasms (7). Currently, the standard treatment for patients with $\mathrm{ABCs}$ is intralesional curettage and bone grafting. The specific concerns associated with the surgery are as follows: Controlling bleeding from the cavity and the high local recurrence rate of $\sim 8-25 \%$ following curettage. In 1962 , Jaffe reported the possibility that ABCs may be preceded by other bony lesions (8). After that various preexisting bone lesions including fibrous dysplasia, giant cell tumors, chondroblastomas and non-ossifying fibromas were reported (9-16). It is crucial to be able to distinguish $\mathrm{ABCs}$ from other bone tumors, in order to select the most appropriate treatment for each case. In the present study, a total of 22 cases of primary and secondary ABCs from patients who were treated at Department of Orthopedic Surgery, Kagoshima University Hospital (Kagoshima, Japan) from 2001-2015, are reviewed and discussed. Although a number of previous studies have evaluated the characteristic features of ABCs, only a few have focused on the differential diagnosis of primary and secondary ABCs $(8,17)$. The aim of the present study was to appraise the various treatment outcomes for $\mathrm{ABC}$ and present a diagnostic algorithm for primary and secondary ABCs.

\section{Materials and methods}

The present study conducted retrospective review of the cases of 22 patients treated for ABCs at Department of Orthopedic 
Table I. Summary of the 11 cases of patients with primary ABC.

\begin{tabular}{rrrll}
\hline No. & Gender & Age (years) & Lesion location & Treatment \\
\hline 1 & F & 6 & Femoral metaphysis & C+B \\
2 & M & 10 & Tibial metaphysis & C+B \\
3 & M & 11 & Ischium & C+B \\
4 & M & 11 & Tibial metaphysis & C+B \\
5 & F & 13 & Radial diaphysis & Bisphosphonate \\
6 & M & 16 & Humeral metaphysis & C+B \\
7 & M & 16 & Pubis & C+B \\
8 & M & 17 & Ilium & C+B \\
9 & F & 22 & Talus & C+B \\
10 & M & 26 & Femoral metaphysis & C+B \\
11 & M & 49 & Femoral metaphysis & C+B+fixation \\
\hline
\end{tabular}

$\mathrm{C}+\mathrm{B}$, curettage and bone grafting; $\mathrm{F}$, female; $\mathrm{M}$, male; $\mathrm{ABC}$, aneurysmal bone cyst.

Surgery, Kagoshima University between January 2001 to March 2015. Both primary and secondary ABCs were included in the present study. Open biopsy including intraoperative pathological diagnosis was performed in all patients. A total of 21 patients received surgical treatments of curettage with bone grafting or polymethyl methacrylate (PMMA) cementing, while one patient treated with bisphosphonate instead of surgical treatment.

The data were obtained from office and hospital charts. The obtained data were preoperative images such as X-ray, computerized tomography (CT) and magnetic resonance imaging (MRI) analyses, and patient's data including age, gender, tumor location and symptoms, serum alkaline phosphatase (ALP) levels, the type of treatment administered, pathological results and if recurrence was observed.

In order to establish a diagnostic algorithm for $\mathrm{ABC}$, the age, tumor location (metaphysis, epiphysis or diaphysis) and serum ALP level elevation of the patient was reviewed in all cases. According to a previous study regarding the characteristics of an MRI of telangiectatic osteosarcoma (TOS) (18), we reviewed the preoperative MRI images particularly for the presence of cortical destruction or soft tissue masses for discriminating between $\mathrm{ABC}$ and TOS. Informed consent from all patients were obtained for the use of samples and the publication of their data.

\section{Results}

A total of 11 patients were diagnosed with primary ABC (Table I), including eight males and three females. The age range of primary $\mathrm{ABC}$ was 6-49 years and the mean age was 17.9 years. Eight of the lesions involved the metaphysis of the long bones and three lesions occurred in the pelvis. The treatment administered was curettage and artificial bone grafting, with an intraoperative pathological diagnosis in 10/11 cases. One patient also had a preoperative pathological fracture and was treated with an internal fixation during the surgery. The $\mathrm{ABC}$ in the no. 5 patient affected the diaphysis of the radius; the patient consented to treatment with bisphosphonates instead of surgery. As the lesion existed in the radius close to the ulnar, the patient presented with dysfunction such as nerve palsy and limitation of wrist range of motion following surgery were concerned. Three months following the administration of bisphosphonate therapy, the patient reported the complete disappearance of pain, and a good degree of bone remodeling was identified by X-ray imaging. Furthermore, a satisfactory treatment outcome was obtained and no evidence of dysfunction was observed.

Local recurrence was identified in two patients (18\%). A representative case of a primary $\mathrm{ABC}$, which was identified in the talus and recurred following curettage, is presented in Fig. 1. Radiography revealed a multiloculated osteolytic lesion close to the articular surface of the talus (Fig. 1A). MRI showed multiple cystic lesions and fluid-fluid levels in the cyst. No destruction of cortex and no soft tissue mass were observed in MRI (Fig. 1B). A histological tissue section obtained from the curettage specimen exhibited collagenous tissue with spindle-shaped cells and sporadic multinucleated giant cells (Fig. 1C). Although curettage of the lesion was performed, no adjuvant therapy, including high speed burring, was administered (Fig. 1D). Fifteen months following the surgery, recurrence of the tumor was observed and curettage under scope guidance was performed in order to completely resect the lesion. No further recurrence was identified for five years following the second surgery. However, osteoarthritic changes with associated mild pain were observed. In order to differentially diagnose an ABC from a malignant bone tumor, serum ALP levels and preoperative X-ray and MRI images were analyzed. None of the patients exhibited elevated serum ALP levels and only three cases did not exhibit sclerotic margins around the lesion, as determined by X-ray images. MRI revealed no cases of soft tissue mass and thick septal enhancement.

A total of 11 patients (two male and nine female) were diagnosed with secondary ABC (Table II). All of these cases occurred in the long bones and the accompanying lesions included two fibrous dysplasia, four giant cell tumors, three chondroblastomas and two non-ossifying fibromas. The 
Table II. Summary of 11 patients with secondary ABC.

\begin{tabular}{ccclll}
\hline No. & Gender & Age (years) & \multicolumn{1}{c}{ Location } & Primary bone tumor & Treatment \\
\hline 1 & F & 12 & Femoral diaphysis & Fibrous dysplasia & C+B \\
2 & F & 24 & Femoral diaphysis & Fibrous dysplasia & C+B+fixation \\
3 & M & 26 & Humeral metaphysis & Giant cell tumor & C+B \\
4 & F & 23 & Ulnar metaphysis & Giant cell tumor & C+B \\
5 & F & 34 & Tibial metaphysis & Giant cell tumor & C+P \\
6 & F & 47 & Tibial metaphysis & Giant cell tumor & C+P \\
7 & F & 12 & Femoral head & Chondroblastoma & C+B+fixation \\
8 & M & 16 & Femoral head & Chondroblastoma & Chondroblastoma \\
9 & F & 25 & Greater trochanter & Non ossifying fibroma & C+B \\
10 & F & 10 & Femoral diaphysis & Non ossifying fibroma & C+B \\
\hline
\end{tabular}

$\mathrm{C}+\mathrm{B}$, curettage and bone grafting; $\mathrm{C}+\mathrm{P}$, curettage and PMMA cementing; $\mathrm{M}$, male; $\mathrm{F}$, female; $\mathrm{ABC}$, aneurysmal bone cyst.
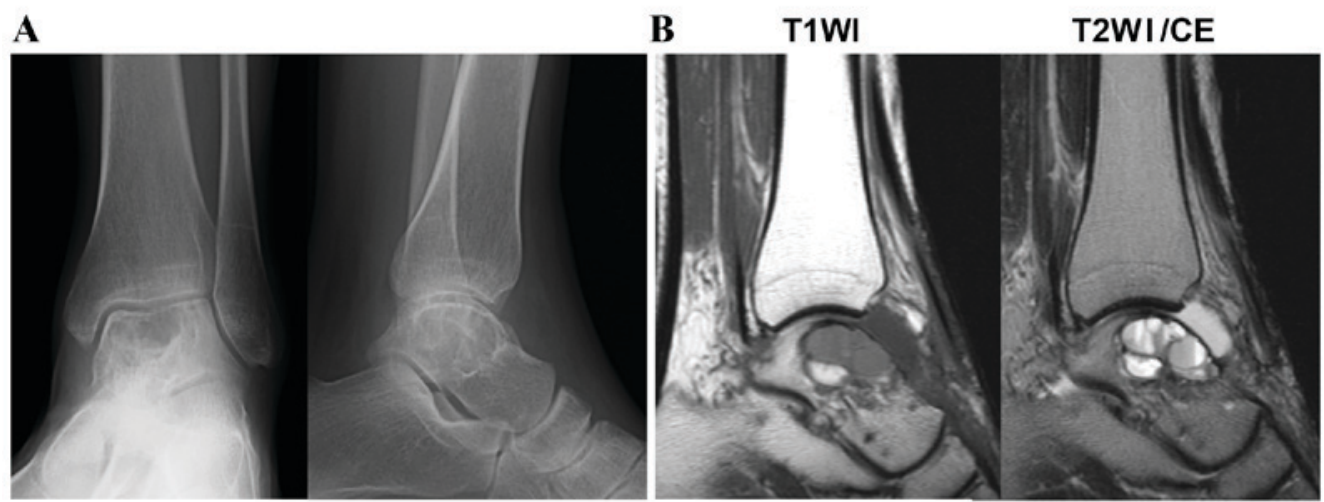

C

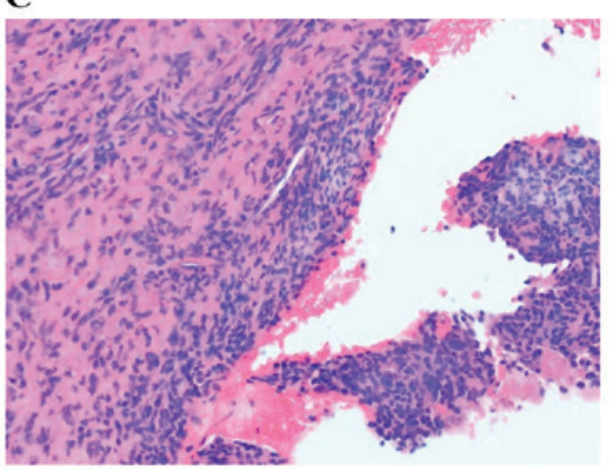

D

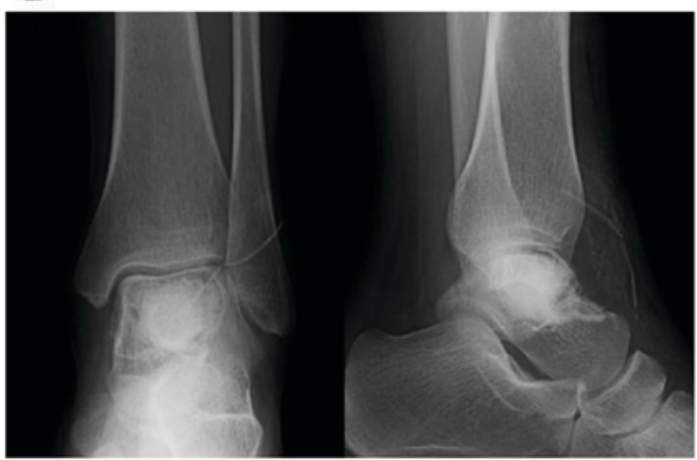

Figure 1. A case of primary ABC that occurred in the talus and recurred following curettage. (A) Radiography revealed a multiloculated osteolytic lesion close to the articular surface of the talus. (B) MRI revealed multiple cystic lesions divided by thin septa. (C) A histological tissue section obtained from the curettage specimen exhibited collagenous tissue with spindle-shaped cells and sporadic multinucleated giant cells. Original magnification, $\mathrm{x} 200$. (D) Postoperative radiography revealed the artificial bone graft in the lesion. T1WI, T1-weighted image; T2WI, T2-weighted image; ABC, aneurysmal bone cyst; MRI, magnetic resonance imaging.

mean ages of the patients were as follows: Fibrous dysplasia, 18 years; giant cell tumor, 32.5 years; chondroblastoma, 17.6 years; non-ossifying fibroma, 13.5 years. The fibrous dysplasia and the non-ossifying fibroma lesions were observed to have developed in the diaphysis, the giant cell tumors in the metaphysis and the chondroblastomas in the epiphysis. The treatment administered to patients with fibrous dysplasia, chondroblastomas and non-ossifying fibromas was curettage and artificial bone grafting, with an intraoperative pathological diagnosis. In 3/4 of the giant cell tumor cases, an open biopsy was performed prior to the surgery. For the two patients in whom the lesion occurred in the upper extremity, aggressive curettage, with adjuvant high speed burring, and artificial bone grafting was performed. By contrast, for the two patients in whom the lesion occurred in the lower extremity, curettage and polymethyl methacrylate cementing was performed. A 
A

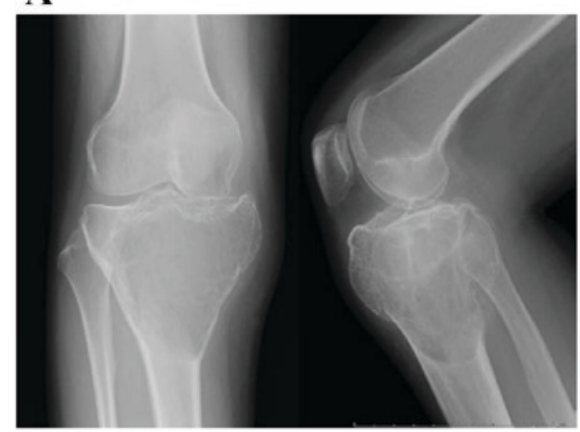

C

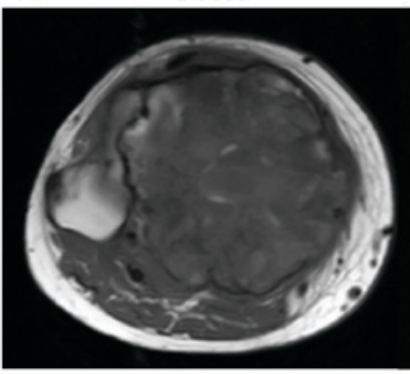

D

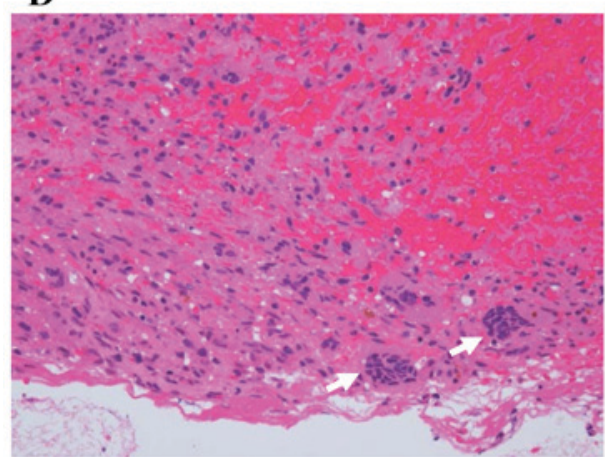

B

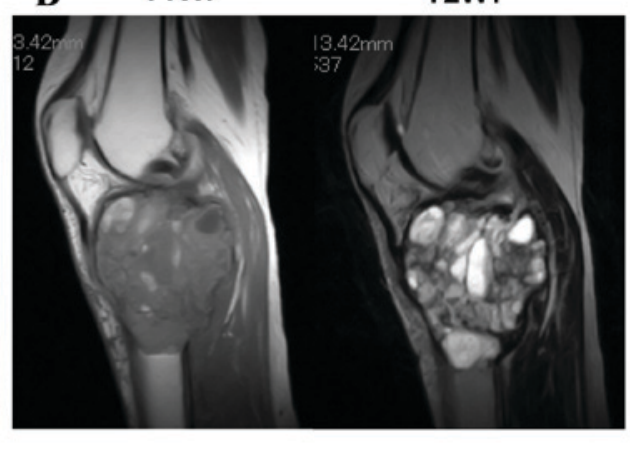

T2WI

T2WI/CE
T2WI
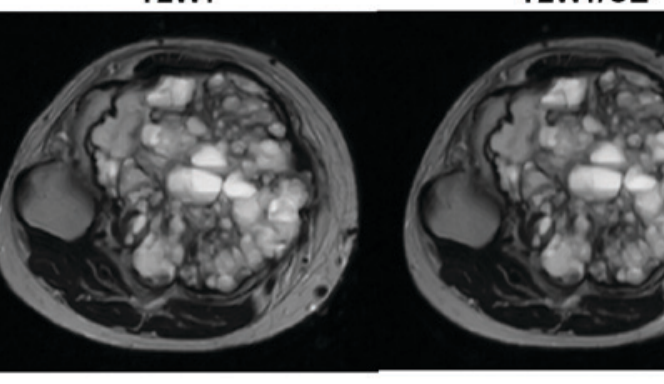

E

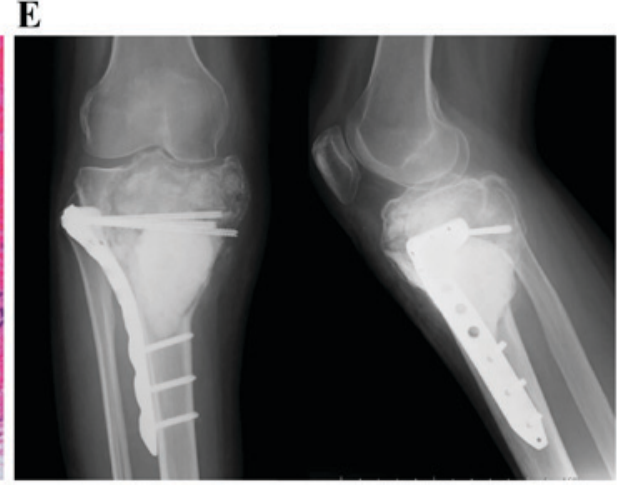

Figure 2. A case of secondary ABC with a giant cell tumor. (A) Radiography demonstrated an eccentric multiloculated osteolytic lesion in the metaphysis of the proximal tibia. (B) Sagittal and (C) axial MRI revealed multiple cystic lesions with a soft tissue mass. (D) A histological tissue biopsy section exhibited stromal cells with round nuclei and multinucleated giant cells (arrows). Original magnification, x200. (E) Following the pathological diagnosis of a giant cell tumor, curettage and PMMA cementing, supported with a locking plate, was performed. T1WI, T1-weighted image; T2WI, T2-weighted image; CE, contrastenhanced imaging; $\mathrm{ABC}$, aneurysmal bone cyst; MRI, magnetic resonance imaging; PMMA, polymethyl methacrylate.

secondary ABC with a giant cell tumor involving proximal Tibia in 33-year-old female is shown (Fig. 2). Plain radiograph demonstrated an eccentric multiloculated osteolytic lesion in the metaphysis of the proximal tibia (Fig. 2A). MRI revealed multiple cystic lesions with a soft tissue mass (Fig. 2B and C). A histological tissue biopsy section exhibited stromal cells with round nuclei and multinucleated giant cells (Fig. 2D). Following the pathological diagnosis of a giant cell tumor, curettage and PMMA cementing, supported with a locking plate, was performed (Fig. 2E).

\section{Discussion}

The clinical features of the cases of primary ABC evaluated in the present study are similar to what has been previously reported. The majority of primary ABCs ( 80\%) occur within the first two decades of life $(3,4)$. Although the most common location of presentation is in the long bones, particularly the femur and tibia, primary ABCs may also occur in flat bones, including the pelvis and vertebrae $(1,2)$. All the cases of primary ABC exhibited a thinning of the cortex and an expansion of the lesion, as determined by $\mathrm{X}$-ray imaging, which is known as the soap-bubble appearance (2). T2-weighted MRI revealed multiple cystic lesions that were divided by a thin septum, and a fluid-filled cyst that indicated a collection of blood (3-5). By contrast, the features of the cases diagnosed as secondary ABC were closely associated with the features of the accompanying lesion. Secondary ABC with fibrous dysplasia and non-ossifying fibroma typically occurs in the diaphysis of long bones in adolescents (16), whereas secondary ABC with chondroblastoma usually occurs in the metaphysis of the long bones in adolescents $(13,15)$. Secondary ABC with giant cell tumors occur in the metaphysis and epiphysis of the long bones in adults $>30$ years of age $(14,17)$. It is possible to distinguish between primary and secondary ABCs based on the features of the preceding bone tumor. For the lesions that exhibit a soft tissue mass in the preoperative MRI, aggressive bone 
Table III. Characteristics of ABC-associated bone tumors as determined by a review of the literature.

\begin{tabular}{|c|c|c|c|c|}
\hline & Age & Location & MRI & Ref.no. \\
\hline \multirow[t]{5}{*}{ Giant cell tumor } & $20-45$ years & Metaphysis and epiphysis & $\begin{array}{l}\text { Useful in assessing the } \\
\text { extent of intraosseous } \\
\text { spread and defining soft } \\
\text { tissue involvement }\end{array}$ & 6 \\
\hline & 20-50 years & Metaphysis and epiphysis & $\begin{array}{l}\text { Cortical destruction, } \\
\text { soft tissue mass }\end{array}$ & 13 \\
\hline & $20-45$ years & Metaphysis and epiphysis & $\begin{array}{l}\text { Low signal on } \mathrm{T} 1 \text { imaging } \\
\text { and a heterogeneously higher } \\
\text { signal on } \mathrm{T} 2 \text { imaging }\end{array}$ & 21 \\
\hline & $20-40$ years & Epiphysis & $\begin{array}{l}\text { Soft tissue mass beyond the } \\
\text { bone cortex or into the } \\
\text { adjacent joint }\end{array}$ & 22 \\
\hline & $32.5(23-47)$ years & Metaphysis & $\begin{array}{l}\text { Soft tissue involvement } \\
(\sim 50 \%)\end{array}$ & $\begin{array}{c}\text { Present } \\
\text { study }\end{array}$ \\
\hline \multirow[t]{4}{*}{ Chondroblastoma } & $10-25$ years & Epiphysis and epimetaphysis & N.D. & 6 \\
\hline & N.D. & Epiphysis and apophysis & N.D. & 23 \\
\hline & Mean age: 19.9 years & Epiphysis and apophysis & N.D. & 24 \\
\hline & $17.7(12-25)$ years & Epiphysis or apophysis & $\begin{array}{l}\text { High signal on } \mathrm{T} 2 \text { imaging } \\
\text { and does not extend the } \\
\text { epiphyseal growth plate }\end{array}$ & $\begin{array}{l}\text { Present } \\
\text { study }\end{array}$ \\
\hline \multirow[t]{3}{*}{ Fibrous dysplasia } & Mean age: 15.0 years & Metaphysis or diaphysis & N.D. & 25 \\
\hline & Mean age: 8 years & Metaphysis or diaphysis & N.D. & 27 \\
\hline & $18(12-24)$ years & Femoral diaphysis & Not specific & $\begin{array}{l}\text { Present } \\
\text { study }\end{array}$ \\
\hline \multirow[t]{4}{*}{$\begin{array}{l}\text { Non-ossifying } \\
\text { fibroma }\end{array}$} & $2-15$ years & $\begin{array}{l}\text { Metaphysis and migrates } \\
\text { toward the diaphysis } \\
\text { with growth }\end{array}$ & N.D. & 28 \\
\hline & $\begin{array}{l}\text { Skeletally immature } \\
\text { children }\end{array}$ & $\begin{array}{l}\text { Metaphysis or the metaphyseal } \\
\text { diaphyseal junction }\end{array}$ & N.D. & 29 \\
\hline & During the growth period & Metaphysis & N.D. & 30 \\
\hline & $13.5(10-17)$ years & Diaphysis & $\begin{array}{l}\text { Primarily located } \\
\text { in the cortex }\end{array}$ & $\begin{array}{c}\text { Present } \\
\text { study }\end{array}$ \\
\hline
\end{tabular}

MRI, magnetic resonance imaging; T1, T1 weighted images; T2, T2 weighted images; N.D, not described; ABC, aneurysmal bone cyst. The present study reviewed literature and summarized the common age, tumor location and characteristic MRI findings. GCT occurs in middle aged patients, and it affect metaphysis and/or epiphysis of long bones. The characteristic feature of MRI is soft tissue mass. Chondroblastoma occurs in adolescent patients, and it affects epiphysis and/or apophysis. Fibrous Dysplasia and Non-ossifying fibroma mainly occur in skeletally immature children, and these affect metaphysis and/or diaphysis.

tumors, including giant cell tumors and osteosarcomas, must be considered. In particular, TOS has occasionally been misdiagnosed as an $\mathrm{ABC}$. TOS is a rare subtype of osteosarcoma that is present in $2-12 \%$ of all osteosarcoma cases (18). TOS is characterized by the presence of numerous blood-filled cavities divided by septa (19,20). Gao et al (21) described various features of TOS, including high serum ALP levels, cortical destruction, the presence of a soft tissue mass and thick septal enhancement, as observed using MRI. In the event that these features are identified preoperatively, a biopsy must be performed prior to the surgery. In order to establish a simplified diagnostic algorithm for ABC and other types of cystic bone tumors, a review of the previous literature regarding the clinical characteristics and the imaging features of ABC-associated tumors was performed (14,22-31). The patient age, tumor location and MRI results, which are essential for the identification of ABC-associated tumors, were summarized and presented in Table III. According to these features (Table III), and to the results of the present study (Tables I and II), a diagnostic flowchart was proposed for primary and secondary ABCs (Fig. 3) (10,13-16). As indicated in Fig. 3, a primary diagnosis may be established, with a subsequent imaging study or biopsy to be performed for the determination of a final diagnosis. 


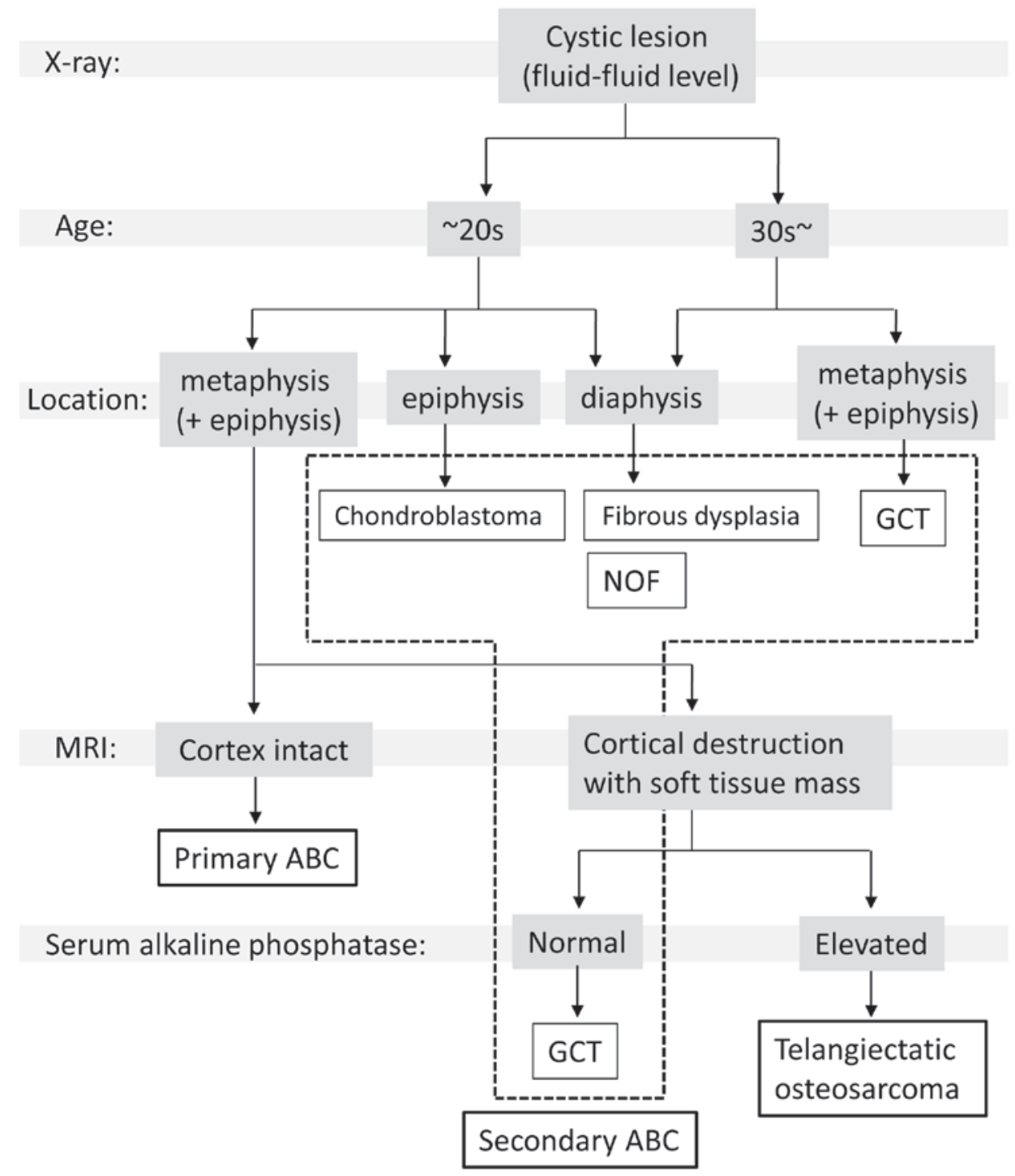

Figure 3. A simplified flowchart to facilitate discrimination between $\mathrm{ABC}$ and other types of bone tumors during diagnosis. Patients with bone tumors exhibited multiple cystic lesions in X-rays are first stratified by age. In patients $\geq 30$ years old, the occurrence of a secondary ABC following a fibrous dysplasia or giant cell tumor should be considered. Subsequently, based on the location of the initial lesion, a primary differential diagnosis may be established. In patients $<30$ years old with a lesion in the metaphysis, cortex destruction must be evaluated using MRI. If the cortex is intact, the most likely diagnosis is primary ABC. If the cortex is degenerating and a soft tissue mass is present, an aggressive bone tumor, including a giant cell tumor or telangiectatic osteosarcoma, must be considered. In cases with elevated serum alkaline phosphatase levels, a telangiectatic osteosarcoma is possible. ABC, aneurysmal bone cyst; MRI, magnetic resonance imaging; GCT, Giant cell tumor; NOF, Non ossifying fibroma.

One of the challenges of the current recommended treatment for $\mathrm{ABC}$ is the high rate of tumor recurrence following surgery (12). The most common treatment for $\mathrm{ABC}$ is extended curettage and bone grafting, intended to reestablish normal anatomy and function (2). In one of the recurrence cases of the current study, the lesion had developed close to the growth plate of the distal tibia. In another case, the lesion had affected the talus and had developed close to the ankle joint. Insufficient curettage, typically due to the surgeon attempting to avoid damage to the growth plate and articular cartilage, is one possible cause of local lesion recurrence. Various post-curettage adjuvant therapies have been proposed to reduce the rate of recurrence, including phenol cauterization, cryosurgery, argon beam coagulation and high-speed burring (32-35). Although high speed burring was occasionally performed following the extended curettage of primary ABCs in in the present study, no adjuvant therapy was administered during the primary curettage of the recurrence cases. For those cases, one of the aforementioned adjuvant therapies may have been considered for use following curettage. Numerous previous studies have demonstrated that bisphosphonate therapy was effective for patients with unresectable and symptomatic benign bone tumors (36-39). Although surgery is currently the standard therapy for primary ABCs, bisphosphonates may be potentially efficacious approach for unresectable and recurrent lesions.

In conclusion, distinguishing between primary and secondary ABCs is relatively simple based on the clinicopathological features of the patient, including tumor location and patient age. In the event that a preoperative diagnosis based on the flowchart created during the current study is not possible, a biopsy must be considered prior to curettage. In order to prevent local recurrence, an adjuvant therapy may also be considered during the surgery. 


\section{References}

1. Ruiter DJ, van Rijssel TG and van der Velde EA: Aneurysma bone cysts: A clinicopathological study of 105 cases. Cancer 39: 2231-2239, 1977

2. Capanna R, Campanacci DA and Manfrini M: Unicameral and aneurysmal bone cysts. Orthop Clin North Am 27: 605-614, 1996.

3. Gibbs CP Jr, Hefele MC, Peabody TD, Montag AG, Aithal V and Simon MA: Aneurysmal bone cyst of the extremities. Factors related to local recurrence after curettage with a high-speed burr. J Bone Joint Surg Am 81: 1671-1678, 1999.

4. Bollini G, Jouve JL, Cottalorda J, Petit P, Panuel M and Jacquemier M: Aneurysmal bone cyst in children: Analysis of twenty-seven patients. J Pediatr Orthop B 7: 274-285, 1998.

5. Boubbou M, Atarraf K, Chater L, Afifi A and Tizniti S: Aneurysmal bone cyst primary-about eight pediatric cases: Radiological aspects and review of the literature. Pan Afr Med J 15: 111, 2013

6. Fletcher CDM, World Health Organization: International Agency for Research on Cancer. WHO classification of tumours of soft tissue and bone. 4th editon. Fletcher CDM (ed). Lyon, IARC Press, 468, 2013.

7. Oliveira AM, Perez-Atayde AR, Inwards CY, Medeiros F, Derr V, Hsi BL, Gebhardt MC, Rosenberg AE and Fletcher JA: USP6 and CDH11 oncogenes identify the neoplastic cell in primary aneurysmal bone cysts and are absent in so-called secondary aneurysmal bone cysts. Am J Pathol 165: 1773-1780, 2004.

8. Martinez V and Sissons HA: Aneurysmal bone cyst. A review of 123 cases including primary lesions and those secondary to other bone pathology. Cancer 61: 2291-2304, 1988.

9. Yamamoto M, Urakawa H, Nishida Y and Hirata H: Secondary aneurysmal bone cyst in the distal humerus after resection of intra-articular nodular fasciitis of the elbow. BMC Res Notes 8: 311,2015

10. Sakamoto A, Ishii T, Oda Y and Iwamoto Y: Nonossifying fibroma presenting as an aneurysmal bone cyst: A case report. J Med Case Rep 6: 407, 2012.

11. Bahk WJ and Mirra JM: Differential diagnostic value of 'blue reticulated chondroid-like material' in aneurysmal bone cysts: A classic histopathologic analysis of 215 cases. Am J Clin Pathol 143: 823-829, 2015.

12. Tay T, Wong SB, Sittampalam Ks and Lie DT: Clear cell chondrosarcoma with secondary aneurysmal bone cyst changes. Singapore Med J 55: e49-e51, 2014.

13. Sailhan F, Chotel F and Parot R; SOFOP: Chondroblastoma of bone in a pediatric population. J Bone Joint Surg Am 91: 2159-2168, 2009.

14. Chakarun CJ, Forrester DM, Gottsegen CJ, Patel DB, White EA and Matcuk GR Jr: Giant cell tumor of bone: Review, mimics, and new developments in treatment. Radiographics 33: 197-211, 2013.

15. Chung JW and Lee HS: Secondary aneurysmal bone cystic change of the chondroblastoma, mistaken for a primary aneurysmal bone cyst in the patella. Knee Surg Relat Res 26: 48-51, 2014.

16. Anderson N, DiBella C, Pianta M, Slavin J and Choong P: Aggressive aneurysmal bone cyst in association with polyostotic fibrous dysplasia: A case report. Int J Surg Case Rep 12: 52-56, 2015.

17. Tomasik P, Spindel J, Miszczyk L, Chrobok A, Koczy B, Widuchowski J, Mrozek T, Matysiakiewicz J and Pilecki B: Treatment and differential diagnosis of aneurysmal bone cyst based on our own experience. Ortop Traumatol Rehabil 11: 467-475, 2009.

18. Huvos AG, Rosen G, Bretsky SS and Butler A: Telangiectatic osteogenic sarcoma: A clinicopathologic study of 124 patients. Cancer 49: 1679-1689, 1982.
19. Saito T, Oda Y, Kawaguchi K, Tanaka K, Matsuda S, Sakamoto A, Iwamoto Y and Tsuneyoshi M: Five-year evolution of a telangiectatic osteosarcoma initially managed as an aneurysmal bone cyst. Skeletal Radiol 34: 290-294, 2005.

20. Colomina J, Peiro A, Trullols L and Garcia I: Telangiectatic osteosarcoma. J Orthop Surg (Hong Kong) 21: 96-99, 2013.

21. Gao ZH, Yin JQ, Liu DW, Meng QF and Li JP: Preoperative easily misdiagnosed telangiectatic osteosarcoma: Clinical-radiologic-pathologic correlations. Cancer Imaging 13: 520-526, 2013.

22. Amanatullah DF, Clark TR, Lopez MJ, Borys D and Tamurian RM: Giant cell tumor of bone. Orthopedics 37: 112-120, 2014.

23. Sobti A, Agrawal P, Agarwala S and Agarwal M: Giant cell tumor of bone-an overview. Arch Bone Jt Surg 4: 2-9, 2016.

24. Maheshwari AV, Jelinek JS, Song AJ, Nelson KJ, Murphey MD and Henshaw RM: Metaphyseal and diaphyseal chondroblastomas. Skeletal Radiol 40: 1563-1573, 2011.

25. Douis H and Saifuddin A: The imaging of cartilaginous bone tumours. I. Benign lesions. Skeletal Radiol 41: 1195-1212, 2012.

26. Ippolito E, Bray EW, Corsi A, De Maio F, Exner UG, Robey PG, Grill F, Lala R, Massobrio M, Pinggera O, et al: Natural history and treatment of fibrous dysplasia of bone: A multicenter clinicopathologic study promoted by the European pediatric orthopaedic society. J Pediatr Orthop B 12: 155-177, 2003.

27. Nixon GW and Condon VR: Epiphyseal involvement in polyostotic fibrous dysplasia. A report of two cases. Radiology 106: 167-170, 1973.

28. Harris WH, Dudley HR Jr and Barry RJ: The natural history of fibrous dysplasia. An orthopaedic, pathological, and roentgenographic study. J Bone Joint Surg Am 44-A: 207-233, 1962.

29. Noh JH, Ryu KN, Bae JY, Roh YH and Choi IS: Nonossifying fibroma developed in metaphysis and epiphysis-a case report. Ann Diagn Pathol 17: 207-209, 2013

30. Betsy M, Kupersmith LM and Springfield DS: Metaphyseal fibrous defects. J Am Acad Orthop Surg 12: 89-95, 2004.

31. Ritschl P, Karnel F and Hajek P: Fibrous metaphyseal defects-determination of their origin and natural history using a radiomorphological study. Skeletal Radiol 17: 8-15, 1988.

32. Reddy KI, Sinnaeve F, Gaston CL, Grimer RJ and Carter SR Aneurysmal bone cysts: Do simple treatments work? Clin Orthop Relat Res 472: 1901-1910, 2014.

33. Peeters SP, Van der Geest IC, de Rooy JW, Veth RP and Schreuder HW: Aneurysmal bone cyst: The role of cryosurgery as local adjuvant treatment. J Surg Oncol 100: 719-724, 2009.

34. Cummings JE, Smith RA and Heck RK Jr: Argon beam coagulation as adjuvant treatment after curettage of aneurysmal bone cysts: A preliminary study. Clin Orthop Relat Res 468: 231-237, 2010.

35. Wang EH, Marfori ML, Serrano MV and Rubio DA: Is curettage and high-speed burring sufficient treatment for aneurysmal bone cysts? Clin Orthop Relat Res 472: 3483-3488, 2014.

36. Cornelis F, Truchetet ME, Amoretti N, Verdier D, Fournier C, Pillet O, Gille $\mathrm{O}$ and Hauger O: Bisphosphonate therapy for unresectable symptomatic benign bone tumors: A long-term prospective study of tolerance and efficacy. Bone 58: 11-16, 2014.

37. Branstetter DG, Nelson SD, Manivel JC, Blay JY, Chawla S, Thomas DM, Jun S and Jacobs I: Denosumab induces tumor reduction and bone formation in patients with giant-cell tumor of bone. Clin Cancer Res 18: 4415-4424, 2012.

38. Sivendran S, Harvey H, Lipton A and Drabick J: Treatment of Langerhans cell histiocytosis bone lesions with zoledronic acid: A case series. Int J Hematol 93: 782-786, 2011.

39. Lange T, Stehling C, Fröhlich B, Klingenhöfer M, Kunkel P, Schneppenheim R, Escherich G, Gosheger G, Hardes J, Jürgens H and Schulte TL: Denosumab: A potential new and innovative treatment option for aneurysmal bone cysts. Eur Spine J 22: $1417-1422,2013$ 